\title{
Constitution of the Ependyma in the Chicken Telencephalon
}

\author{
Shinsuke UCHIDA ${ }^{1,2)}$, Tomohiro IMAGAWA ${ }^{2) *}$, Masato FURUE ${ }^{1,2)}$, Safwat Ali Mohamed ALI ${ }^{1,2)}$, \\ Yoshinao Z. HOSAKA ${ }^{2)}$ and Masato UEHARA ${ }^{2)}$ \\ ${ }^{1)}$ The United Graduate School of Veterinary Science, Yamaguchi University, 1677-1 Yoshida, Yamaguchi 753-8515 and \\ ${ }^{2)}$ Department of Veterinary Medicine, Tottori University, 4-101 Koyama-Minami, Tottori 680-8553, Japan
}

(Received 1 September 2010/Accepted 14 October 2010/Published online in J-STAGE 28 October 2010)

ABSTRACT. The constitution of ependyma derived from the ventricular zone is different from that derived from other regions of the central nervous system. In the mammalian cerebrum, the ependyma is varied by the regions to cortex or basal ganglia (BG). In the avian telencephalon (Tc), previous studies about the constitution of the ependyma have not revealed clear findings. In the present study, we performed immunostaining of ependymal cells in the chicken Tc to confirm differences in the ependyma of various regions. As a result, 4 patterns of ependyma were defined in the outer side of the lateral ventricle. In the base of the lamina pallio-subpallialis (LPS), ependyma consisted of vimentin/glial fibrillary acidic protein (GFAP) double-positive cells, whereas in the base of the lamina frontalis superior, it consisted primarily of vimentin-positive cells and a small number of vimentin/GFAP double-positive cells. With the exception of the above, the pallial ependyma was a single layer containing vimentin single-positive cells. Lastly, the ependyma of the BG was rich in vimentin single-positive cells. The constitutional differences of the ependyma of the pallium and BG concerned differences in ependymal morphology and cell characteristics. These finding suggest that the bounder between pallium and BG is LPS at the point of ependyma. KEY WORDS: ependyma, GFAP, vimentin.

J. Vet. Med. Sci. 73(3): 319-323, 2011

Ependymal cells located along the ventricles have numerous functions and have always been considered glial cells, especially, being more related to astroglial cells, an intermediate between ependymocytes and astroglial cells known as radial glial cells $[3,10,18,26]$. Ependyma is derived from the proliferative ventricular zone (VZ) where ependymal cells develop from radial glial cells. The ependyma in neurogenetic regions of adult vertebrate brains contains various types of cells $[2,4,6,20]$. In various vertebrates, these cells all contain the intermediate filament vimentin (Vim) $[17$, 24]. In adult mammals, it is reported that glial fibrillary acidic protein (GFAP) is contained in not only mature astrocytes $[17,18]$ but also a part of ependyma $[8,11]$.

The cerebrum of mammals is composed of the basal ganglia (BG) located in the ventral region of the lateral ventricle (LV) and the cortex that wraps around the BG. It has long been recognized that pallial regions in the avian telencephalon (Tc) correspond to the cerebral cortex in mammals but are confined to the surface in avian specimens as most avian Tc is just hypertrophied BG $[1,9,15]$. However, recent neurochemistry, hodology, neurogenesis, and functional studies have revealed that most avian Tc exists in the region that was previously thought to be the basal ganglia, but is in fact homologous to the mammalian cerebral cortex [14, 21, 22]. Therefore, the Avian Brain Nomenclature Forum has recommended changing the name of some Tc regions [13, 23]. In our previous study, on the basis of the distribution of glial elements, chicken Tc was divided into the BG and the pallium. The pallium was further sub-divided into 4 com-

\footnotetext{
* Correspondence to: Imagawa, T., Department of Veterinary Medicine, Tottori University, 4-101 Koyama-Minami, Tottori 680-8553, Japan.

e-mail: imagawat@muses.tottori-u.ac.jp
}

partments [27].

Here, we examined the expression of Vim and GFAP to investigate the differences in chicken ependymal elements according to Tc region. In addition, we also compared the compartments of the Tc.

\section{MATERIALS AND METHODS}

Animals and tissue preparation: Three White Leghorn chickens 30 days post-hatch were used. All experiments were conducted in compliance with the guidelines of the Animal Care and Use Committee of Tottori University and the AVAA Guidelines on Euthanasia.

Animals were deeply anaesthetized with diethyl ether and perfused transcardially with a solution of $4 \%$ paraformaldehyde in $0.1 \mathrm{M}$ phosphate buffer $\left(\mathrm{pH} \mathrm{7.6)}\right.$ at $4{ }^{\circ} \mathrm{C}$. After decapitation or perfusion, the Tc was removed and fixed by immersion in the same solution overnight at $4^{\circ} \mathrm{C}$. Next, the tissues were dehydrated with a series of ethanol solutions and embedded in paraffin. Transverse and sagittal sections (10 $\mu \mathrm{m}$ thick) were cut on a sliding microtome. The axis of the transverse section is shown in Fig. 1. The sections were then processed for immunohistochemistry against GFAP and Vim, or for thionin staining according to Nissl.

Immunohistochemistry: Sections were rinsed twice in $0.01 \mathrm{M}$ phosphate buffered saline ( $\mathrm{pH} 7.4$ ) with $0.03 \%$ Triton-X (PBS-T) for $10 \mathrm{~min}$, and were pretreated with $1 \mathrm{mM}$ EDTA ( $\mathrm{pH} \mathrm{8.0)}$ for $3 \mathrm{~min}$ in an autoclave to remove the effect of aldehydes on the antigen-determinant groups. This was followed by incubation in $1 \%$ normal rabbit serum for $30 \mathrm{~min}$ at room temperature to avoid nonspecific background staining. A PBS-T rinse was performed after all preparation steps to neutralize any reagent residues. For 

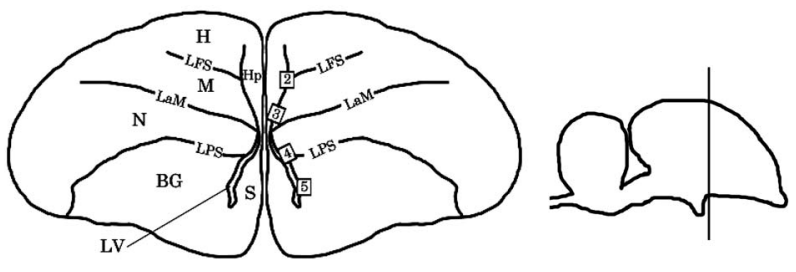

a

$\mathrm{b}$

Fig. 1. Scheme of young (P30) chicken telencephalon. a: Transverse section of the chicken Tc. Numbers in the right hemisphere indicate the location of the images displayed in Figs. 2-5. b: Sagittal section of the chicken brain. The line indicates the axis of the transverse section. BG, basal ganglia; H, hyperpallium; Hp, hippocampus; LaM, lamina mesopallialis; LFS, lamina frontalis superior; LPS, lamina pallio-subpallialis; LV, lateral ventricle; M, mesopallium; N, nidopallium; S, septum.
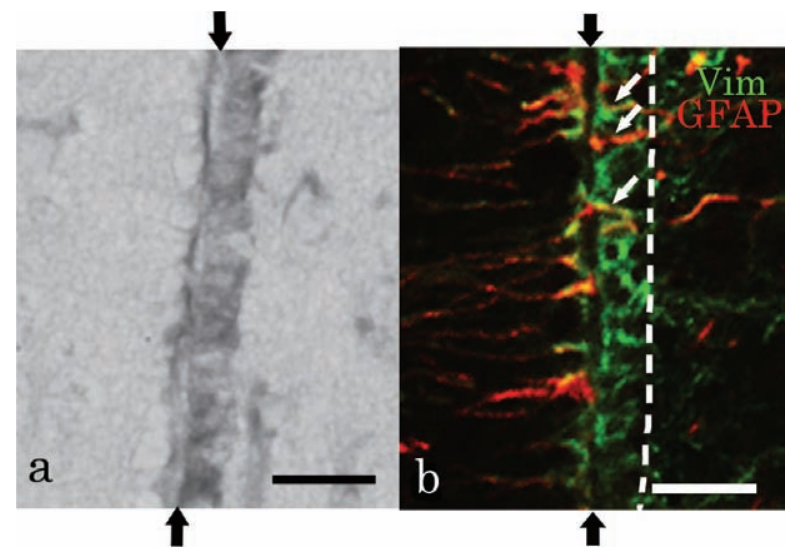

Fig. 2. Nissl staining (a) and double immunostaining for Vim and GFAP (b) around the LV at the LFS level. The medial plane of the LV, i.e. the Hp (left side of the figures), shows low ependymal cells and long processes at the level of the LFS. Almost all of the cells in the ependyma express both Vim and GFAP. In the LFS, most cells in the ependyma express only Vim, but a few cells express both Vim and GFAP (white arrows). The broken line in (b) shows the boundary between the ependyma and parenchyma. The black arrows indicate the location of the LV. Scale bars $=25 \mu \mathrm{m}$.

immunohistochemistry, primary antibodies were mouse monoclonal antibodies against GFAP (1:400, Sigma, U.S.A.) or against Vim (VIM3B4, 1:100, Progen, Germany). Sections were incubated with the primary antibodies overnight at $4^{\circ} \mathrm{C}$. The secondary biotinylated antimouse antibody (ABC kit, Nichirei, Japan) and streptavidinHRP complex (ABC kit, Nichirei) were applied, and immunocomplexes were visualized using 3,3'-diaminobenzidine with $0.006 \% \mathrm{H}_{2} \mathrm{O}_{2}$. Sections were rinsed in distilled water, mounted, and observed under a light microscope. For double-labeled immunostaining, rabbit anti-GFAP (pre-diluted, Nichirei) and mouse monoclonal antibody against Vim (VIM3B4, 1:100, Progen) were used as primary antibody, while rhodamine conjugated donkey anti-rabbit IgG $(1: 100$, Chemicon, Japan) and fluorescein isothiocyanate conju-

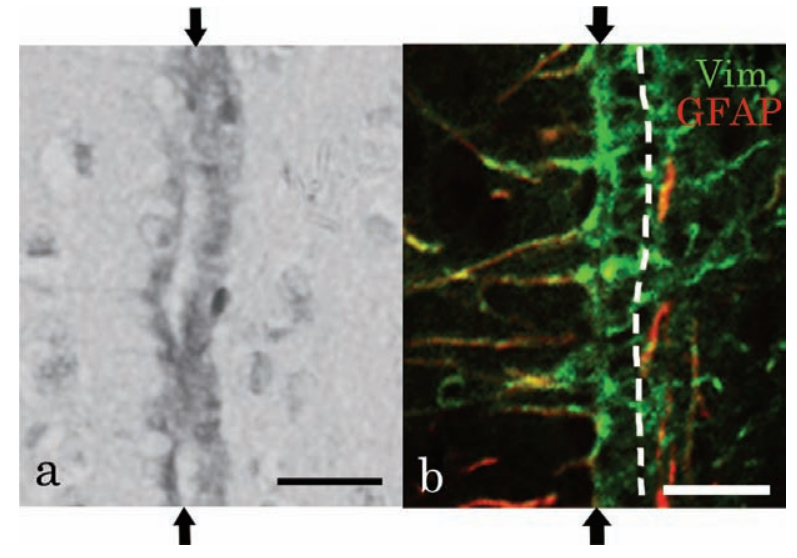

Fig. 3. Nissl staining (a) and double immunostaining of Vim and GFAP (b) around the LV in the mesopallium. Ependyma is thinner than other regions and cells contain only Vim on the outer side of the LV. The broken line in (b) shows the boundary between the ependyma and parenchyma. The black arrows indicate the location of the LV. Scale bars $=25 \mu \mathrm{m}$.

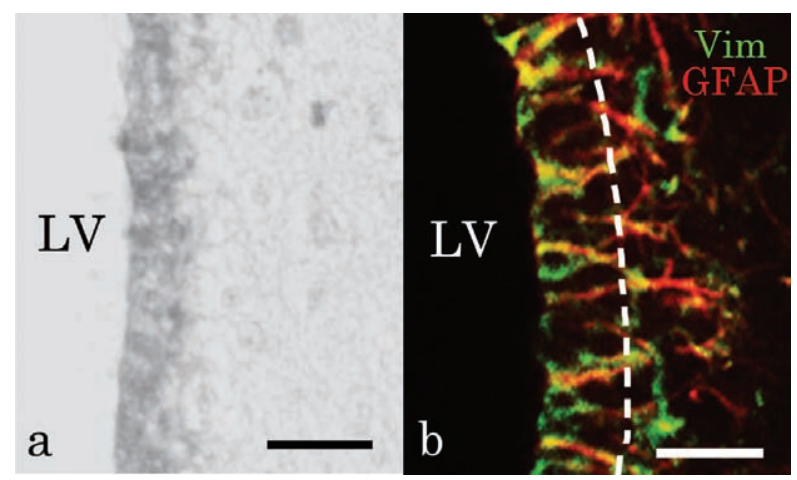

Fig. 4. Nissl staining (a) and double immunostaining of Vim and GFAP (b) around the LV at the LPS level. The ependyma is thick and almost all ependymal cells express both Vim and GFAP. The broken line in (b) shows the boundary between the ependyma and parenchyma. Scale bars $=25 \mu \mathrm{m}$.

gated donkey anti-mouse IgG (1:100, Chemicon) were used for secondary antibody. Thereafter, sections were rinsed and observed under a light microscope. Specimens were incubated in a moist chamber and antibodies were diluted in PBS-T. For identification and nomenclature of chicken Tc regions, we consulted the stereotaxic atlas of Kuenzel and Masson (1988) [16].

\section{RESULTS}

All ependymal layers were lined with Nissl-positive cells. Height and immunoreaction of the various ependymal layers differed according to location around the LV. On the inner side of the LV, 2 patterns of ependyma were observed following immunostaining, while the outer side of the LV showed 4 distinct patterns.

Ependyma on the inner side of the $L V$ : In the dorsal 


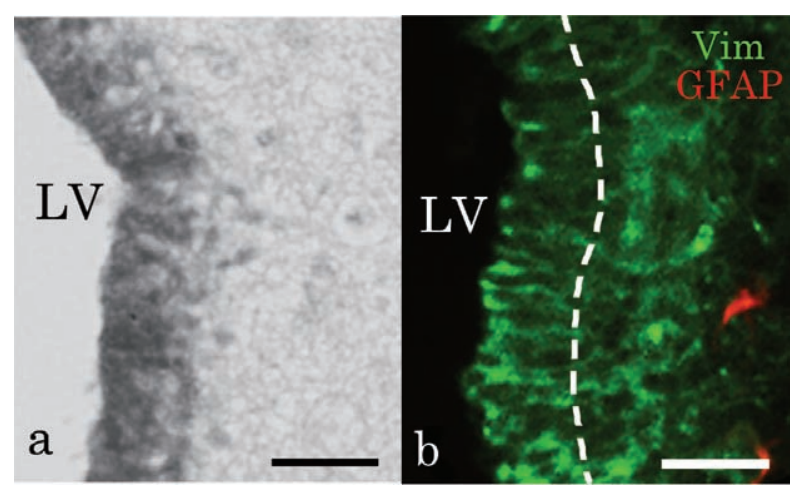

Fig. 5. Nissl staining (a) and double immunostaining of Vim and GFAP (b) around the LV in the BG. Ependyma is thick and GFAP-positive cells or processes are lacking in this vast area which includes the ependyma, although Vim-positive cells are abundant in this area. Layers of Vim-positive cells are thicker than the areas with strong Nissl positive staining, i.e. the ependyma. There are many star-shaped GFAP-positive cells in an area distant from the LV. The ependymal cells form several layers and almost all express only Vim. The broken line in (b) shows the boundary between the ependyma and parenchyma. Scale bars $=25 \mu \mathrm{m}$.

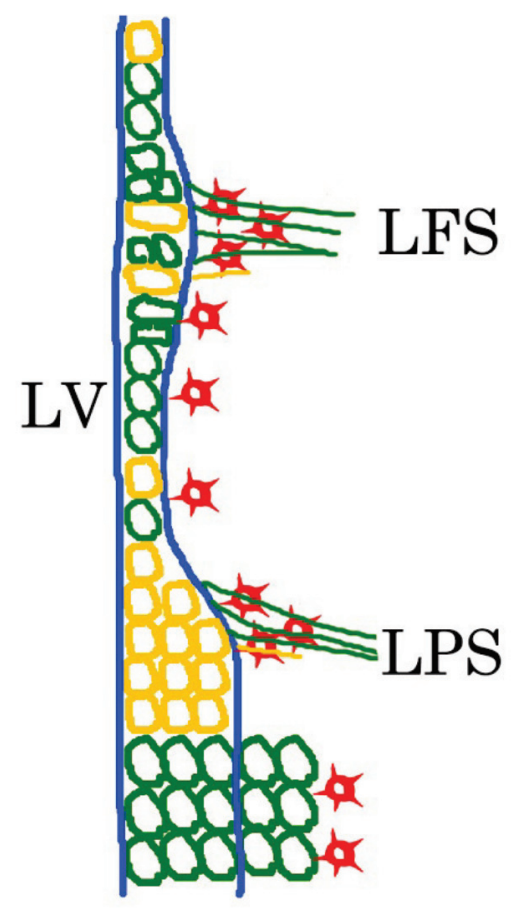

Fig. 6. Schematic drawing of the distributions of the Vim (green)- and GFAP (red)-positive cells in the ependyma on the outer side of LV. The ependyma is enclosed by a blue line. Areas rich in Vim/GFAP double-positive cells (yellow) exist around the LFS and LPS and have a thick ependyma. In the BG, although there are only a few Vim/GFAP double-positive cells, the ependyma is thick and Vim-positive cells are present in the outer ependyma. Red cells are astrocytes in the outer ependyma. region including the hippocampus $(\mathrm{Hp})$, the ependyma consisted of small pyramidal or squamous cells arranged in a single layer along the LV (Fig. 2a). These cells possessed both Vim and GFAP with a single long process (Fig. 2b).

In the ventral region, namely, the septum, ependyma comprised low cubic pseudostratified epithelium of 3-4 layers. Most of these cells possessed neither Vim nor GFAP. Vim/GFAP double-positive $\left(\mathrm{Vim}^{+} / \mathrm{GFAP}^{+}\right)$cells with fine processes were observed in the outer ependyma.

Ependyma of the outer side of the $L V$ : On the dorsal edge of the LV and around the base of the lamina frontalis superior (LFS), the ependyma consisted of simple columnar or stratified high cuboidal epithelium (Fig. 2a). Most of the cells in the ependyma contained Vim, and these cells extended $\mathrm{Vim}^{+}$in a single long process. Some $\mathrm{Vim}^{+}$cells also contained GFAP (Fig. 2b).

In the hyperpallium $(\mathrm{H})$, mesopallium $(\mathrm{M})$, and nidopallium $(\mathrm{N})$, ependyma consisted of simple low cuboidal epithelium along the LV (Fig. 3a). Almost all cells expressed Vim, while few expressed both Vim and GFAP (Fig. 3b).

Around the base of the lamina pallio-subpallialis (LPS), the ependyma consisted of thick stratified cubic cells (Fig. $4 a$ ), which contained only Vim or Vim/ GFAP in the cell bodies, and extended $\mathrm{Vim}^{+}$or $\mathrm{Vim}^{+} / \mathrm{GFAP}^{+}$processes in the outer ependyma (Fig. 4b).

In the $\mathrm{BG}$, the ependyma consisted of a stratification of cubic cells thicker than around the base of the LPS (Fig. 5a). However, most of these cells contained only $\mathrm{Vim}_{\text {and }} \mathrm{Vim}^{+} /$ $\mathrm{GFAP}^{+}$was observed in only a few cells. $\mathrm{Vim}^{+}$cells were observed in the outer ependyma and extended long processes (Fig. 5b).

Results of the outer side of the LV are summarized in Fig. 6. GFAP single-positive cells, possessing several short processes, were observed in the outer ependyma. Sagittal sections showed long $\mathrm{Vim}^{+}$processes extending from the $\mathrm{LV}$ toward the olfactory bulbs (OB) in the LFS and the LPS (data not shown).

\section{DISCUSSION}

Morphological and phylogenetic variation of ependymal cells across various regions of central nervous system has been reported. In chicken and pigeon spinal cord, ependymal cells are immunonegative for both Vim and GFAP [5], although some parts of ependymal cells in chicken optic tectum are immunopositive for GFAP [25]. In adult mammals, the constitution of the ependyma varies by region; the cortex, BG, and OB show differences in the ependyma that derive from differences in the VZ [24]. Therefore, we considered that the differences in ependyma reflect the differences in the Tc compartments in adult birds. In the present study, the morphological differences and the nature of ependymal cells by region were observed in the chicken Tc. On the outer side of the LV, 4 patterns of ependyma were observed, by the variable thickness and immunostaining for Vim and GFAP.

In the adult mammalian cortex, ependyma is simple layer 
and ependymal cells contain only Vim [24]. In the $\mathrm{H}, \mathrm{M}$, and $\mathrm{N}$ (the Tc area other than LFS, LPS, and BG), the ependyma was simple columnar cell layer and the ependymal cells contained Vim, not GFAP. Ependymal cells in the $\mathrm{H}, \mathrm{M}$, and $\mathrm{N}$ may be similar to those of the mammalian cortex. At the point of the ependyma, the $\mathrm{H}, \mathrm{M}$, and $\mathrm{N}$ may be considered as the pallium, although these regions were subdivided by glial developmental distribution [27].

The ependyma of the BG was thick and consisted of $\mathrm{Vim}^{+}$cells with long processes, not of $\mathrm{Vim}^{+} / \mathrm{GFAP}^{+}$cells. In the mammalian BG, ependymal cells are Vim single-positive with long processes, and subependymal cells exist around the ependyma [24]. On the basis of cellular characteristics, the ependyma of the BG in chickens may be similar to that in mammals. The subependymal layers are not detected in lower vertebrate $[12,19]$. The thick $\mathrm{Vim}^{+}$cell layers outer ependyma in the chicken may correspond to the subependymal cells in mammals.

Around the bases of LFS and LPS, $\mathrm{Vim}^{+} / \mathrm{GFAP}^{+}$cells were located while they were few in the other regions. In our previous study, we observed long $\mathrm{Vim}^{+}$processes on the LFS, and LPS from embryo to young. Moreover, these long processes were the bounder of the compartment of the chicken Tc and continued into the OB [27]. In adult mammals, the root named rostral migratory stream (RMS) run from LV to OB, and the base of the RMS in mammals is the boundary between the $\mathrm{BG}$ and white matter $[7,8]$. In the chicken Tc, there were 2 roots (LFS and LPS) from the LV to the OB, but the thicknesses of ependyma were changed between upper and bottom areas in LPS while the thicknesses were not changed between upper and bottom in LFS. This may show that the ependyma of LPS is more similar to the ependyma of RMS than that of LFS. Such findings suggest that the LPS may be the boundary between the BG and the pallium.

Taken together, the constitution and immunoreactivity of the intermediate filaments of the ependymal cells may mediate the compartmentalization of chicken Tc, which would support the new theory of a compartmentalized avian brain $[13,23]$.

\section{REFERENCES}

1. Ariëns-Kappers, C. U., Huber, G. C. and Corsby, E. 1936. The Comparative Anatomy of Nervous System of Vertebrates, Including Man. Hafner, New York.

2. Balercia, G., Bentivoglio, M. and Kruger, L. 1992. Fine structural organization of the ependymal region of the paraventricular nucleus of the rat thalamus and its relation with projection neurons. J. Neurocytol. 21: 105-119.

3. Benjelloun-Touimi, S., Jacque, C. M., Derer, P., De, Vitry, F., Maunory, R. and Dupouey, P. 1985. Evidence that mouse astrocytes may be derived from the radial glia. An immunohistochemical study of the cerebellum in the normal and reeler mouse. J. Neuroimmunol. 9: 87-97.

4. Bjugn, R., Boe, R. and Haugland, H. K. 1988. A stereological study of the ependyma of the mouse spinal cord. With a comparative note on the choroid plexus ependyma. J. Anat. 166: 171-178.
5. Bodega, G., Suárez, I., Rubio, M. and Fernández, B. 1994. Ependyma: phylogenetic evolution of glial fibrillary acidic protein (GFAP) and vimentin expression in vertebrate spinal cord. Histochemistry 102: 113-122.

6. Del, Brío, M. A., Riera, P., García, J. M. and Alvarez-Uría, M. 1991. Cell types of third ventricle wall of the rabbit (Oryctolagus cuniculus). J. Submicrosc. Cytol. Pathol. 23: 147-157.

7. Doetsch, F., Garcia-Verdugo, J. M. and Alvarez-Buylla, A. 1997. Cellular composition and three-dimensional organization of the Subventricular germinal zone in the adult mammalian brain. J. Neurosci. 17: 5046-5061.

8. Doetsch, F., Caille, I., Lim, D. A., Garcia-Verdugo, J. M. and Alvarez-Buylla, A. 1999. Subventricular zone astrocytes are neural stem cells in the adult mammalian brain. Cell 97: 703716.

9. Edinger, L. 1908. The relations of comparative anatomy to comparative psychology. J. Comp. Neurol. Psychol. 18: 437457.

10. Edwards, M. A., Yamamoto, M. and Caviness, V. S. 1990. Organization of radial glia and related cells in the developing mouse CNS. An analysis based upon a new monoclonal antibody marker. Neuroscience 36: 121-144.

11. Garcia, A. D., Doan, N. B., Imura, T., Bush, T. G. and Sofroniew, M. V. 2004. GFAP-expressing progenitors are the principal source of constitutive neurogenesis in adult mouse forebrain. Nat. Neurosci. 7: 1233-1241.

12. García-Verdugo, J. M., Ferrón, S., Flames, N., Collado, L., Desfilis, E. and Font, E. 2002. The proliferative ventricular zone in adult vertebrates: A comparative study using reptiles, birds, and mammals. Brain Res. Bulletin 57: 765-775.

13. Jarvis, E. D., Güntürkün, O., Bruce, L. L., Scillag, A., Karten, H. J., Kuenzel, W., Medina, L., Paxinos, G., Perkel, D. J., Shimizu, T., Striediter, G. F., Wild, J. M., Ball, G. F., DugasFord, J., Durand, S., Hough, G., Husband, S., Kubikova, L., Lee, D. W., Mello, C. V., Powers, A., Siang, C., Smulders, T. V., Wada, K., White, S. A., Yamamoto, K., Yu, J., Reiner, A. and Butler, A. B. 2005. Avian brains and a new understanding of vertebrate brain evolution. Nat. Rev. Neurosci. 6: 151-159.

14. Karten, H. J. 1969. The organization of the avian telencephalon and some speculations on the phylogeny of the amnito telencephalon. pp. 146-179 In: Comparative and Evolutionary Aspects of the Vertebrate Central Nervous System (Noback, C. and Petras, J. eds.), Ann. N.Y. Acad. Sci.

15. Karten, H. J. and Hodos, W. 1967. A Stereotaxic Atlas of the Brain of the Pigeon, Columba livia. The Johns Hopkins University Press, Baltimore.

16. Kuenzel, W. J. and Masson, M. 1988. A Stereotaxic Atlas of the Brain of the Chick (Gallus domesticus). The Johns Hopkins University Press, Baltimore.

17. Lazzari, M. and Franceschini, V. 2006. Glial cytoarchitecture in the central nervous system of the soft-shell turtle, Trionyx sinensis, revealed by intermediate filament immunohistochemistry. Anat. Embryol. 211: 497-506.

18. Levitt, P. and Rakic, P. 1980. Immunoperoxidase localization of glial fibrillary acidic protein in radial glial cells and astrocytes of the developing Rhesus monkey brain. J. Comp. Neurol. 193: 815-840.

19. Martínez-Cerdeño, V., Noctor S. C. and Kriegestein, A. R. 2006. The role of intermediate progenitor cells in the evolutionary expansion of the cerebral cortex. Cereb Cortex 16: i152-i161.

20. Monzón-Mayer, M., Yanes, C., James, J. L. and Sturrock, R. R. 1991. An ultrastructural study of ependymal cell differentiation 
during lizard (Gallotia galloti) midbrain development. J. Anat. 174: 251-261.

21. Puelles, L., Kuwana, E., Puelles, E., Bulfone, A., Shimamura, K., Keleher, J., Smiga, S. and Rubenstein, J. L. 2000. Pallial and subpallial derivatives in the embryonic chick and mouse telencephalon, traced by the expression of the genes Dlx-2, Emx-1, Nkx-2.1, Pax-6, and Tbr-1. J. Comp. Neurol. 424: 409438.

22. Reiner, A., Medina, L. and Veenman, C. L. 1998. Structural and functional evolution of the basal ganglia in vertebrates. Brain Res. Brain Res. Rev. 28: 235-285.

23. Reiner, A., Perkel, D. J., Bruce, L. L., Butler, A. B., Csillag, A., Kuenzel, W., Medina, L., Paxinos, G., Shimizu, T., Striediter, G. F., Wild, M., Ball, G. F., Durand, S., Gütürkün, O., Lee, D. W., Mello, C. V., Powers, A., White, S. A., Hough, G., Kubikova, L., Smulders, T. V., Wada, K., Dugas-Ford, J., Husband, S., Yamamoto, K., Yu, J., Siang, C. and Jarvis, E. D.
2004. Revised nomenclature for avian telencephalon and some related brainstem nuclei. J. Comp. Neurol. 473: 377-414.

24. Roidrígues-Pérez, L. M., Pérez-Martín, M., Jiménez, A. J. and Fernández-Llebrez, P. 2003. Immunocytochemical characterisation of the wall of the bovine lateral ventricle. Cell Tissue Res. 314: 325-335.

25. Shin, D. H., Lee, E. and Cho, S. S. 2003. Glial cells in the chicken optic tectum. Brain Res. 962: 221-225.

26. Suárez, I., Fernández, B., Bodega, G., Tranque, P., Olmos, G. and García-Segura, L. M. 1987. Postnatal development of glial fibrillary acidic protein immunoreactivity in the hamster arcuate nucleus. Dev. Brain Res. 37: 89-95.

27. Uchida, S., Imagawa, T., Shinozaki, A., Furue, M., Safwat, A. M. A., Hosaka, Y. and Uehara, M. 2010. Distribution of astroglial linage cells in the developing chicken telencephalon from embryo to young chick. J. Vet. Med. Sci. 72: 1597-1602. 